\title{
Impact of Classroom Design on Interactive Whiteboard Use in a Special Needs Classroom
}

\author{
Grant Shannon \\ Department of Computer Science \\ Waikato University \\ Hamilton, New Zealand \\ +64 78384021 \\ gjpshannon@gmail.com
}

\author{
Sally Jo Cunningham \\ Department of Computer Science \\ Waikato University \\ Hamilton, New Zealand \\ +6478384402 \\ sallyjo@cs.waikato.ac.nz
}

\begin{abstract}
The physical environment of a classroom-how space is organized and controlled-impacts the use of technology within that setting. This paper presents the initial rationale for choosing an interactive whiteboard (IWB) as the platform for software designed to encourage play in primary students with Autism Spectrum Disorders. An observational study of normal classroom practice and of an installed version of the software uncovered factors in the physical installation of the IWB and its pedagogical use that negatively affect its potential use.
\end{abstract}

\section{INTRODUCTION}

Children with Autism Spectrum Disorders (ASD) don't play in the same way as other children. They often use toys and objects in an inflexible way or become fixated on a certain aspect of the toy they are playing with. For example, a child with ASD may be preoccupied with the spinning wheels on a car, rather than playing a racing or driving game. Some children with ASD do not give any indication that they want to play with other children, preferring to play by themselves; other children with ASD would like to but they can have great difficulty in letting other children know that they want to.

These differences in play may significantly affect a child's social and intellectual development. Play allows children to learn many skills, such as decision-making, turn taking, and significantly, language skills and social interaction, monitoring and reciprocity [9]. Both Piaget [8] and Vygotsky ([11], as referenced in [9]) acknowledged the significance of symbolic play for normal development. According to Vygotsky, play is not parallel to development, but rather one of the forces that drive it.

Support for the development of play is an important feature of the learning day in special needs classrooms. One strategy is to include scheduled "choosing times", in which the students are encouraged to select their own play activity and to engage in it for short periods (typically $10-15$ minutes, several times a day) or longer period (typically 60 minutes, one to three times per week) [2]. The provision of a variety of options for play is crucial-the students must legitimately be able to make a selection from several appealing activities. This also supports a sense of autonomy, enhanced independence, and control in the student (particularly significant for special needs children, who are likely to experience less autonomy through highly structured learning activities and therapies) [4].

In developing a software-based play activity for ASD children, we chose the Interactive Whiteboard (IWB) for its potential to support greater physical ranges of movement in an 'untethered' interaction style than is possible on a PC (Section 2). An observational study of two local special needs classrooms uncovered potential barriers to use in the physical placement of the IWBs and in their association with formal learning exercises (Section 3). A further observation of the installed software confirmed the significance of these barriers to acceptance and accessibility of 'play' software on the IWB (Section 4). In Chapter 5, we place these experiences into the context of earlier research on the effect of classroom organization and IWB placement on effective IWB usage.

\section{RELATED WORK}

The strand of research in recreational software for ASD children that we have chosen to follow is based on moving interaction beyond the keyboard and mouse. Children typically have difficulties in using the keyboard and mouse, and ASD children often lack fine motor control.

A seminal work in this direction is the AURORA project, which aims to develop an autonomous, mobile robot as a therapeutic tool for children with autism. In [3], Dautenhahn describes the benefits of interaction scenarios that allow children to move freely and interact using the whole body and that do not constrain children by requiring them to sit at a desk or wear special devices. The 'embodied interaction' facilitated within environments such as these can provide new aspects to learning, "helping children with autism to explore their bodies and how the body interacts with the environment. Thus, the bodily interaction itself can be as therapeutically relevant as the 'content' of the interaction.” [3].

The scenario presented, of a child interacting with a floor dwelling robot, put forth an argument as to the benefits of 'untethered interaction' that was extremely compelling. "Children with autism often show a distorted and usually 'indifferent' attitude towards their body. Self-injurious behaviour, abnormal complex behaviours of the body and eating disorders can be observed. These indications of body image distortions might contribute to their problems in relating to other people” [3]. The argument is that through the use of 'untethered' interfaces, the learning experience could also become a therapeutic one, where the child is given further opportunity to reconcile their body with the interactions that occur around them.

The 'untethered' principal can be applied to software that runs on platforms other than robots. The ReacTickles Project has developed a suite of recreational software that promotes natural interactions in the form of 'tapping, smoothing, and circling' 
rather than keyboard and mouse interaction; their goal is to develop software that allows children on the autistic spectrum to explore the technology rather than be dominated by it ([6], [7]). This embracing of embodied or untethered technology provides an environment that is more developmentally appropriate for young children as well while side stepping the issues that arise from incompatibilities with more invasive interface technologies for children with ASD (such as environments that use VR helmets or custom harnesses).

Evaluation of the ReacTickles software convincingly demonstrates the benefits that a tangible interface (in this case, the IWB) offers for enhancing the learning capacities of autistic children. The IWB is particularly attractive as a deployment platform because an IWB is installed in many New Zealand special needs primary classrooms. This combination of theoretic justification and practical availability persuaded us to adopt the IWB as our primary platform.

\section{OBSERVATIONAL STUDY}

A local special needs school agreed to allow us to work with their students and staff in our investigations. This work began with a three week observation of two classrooms at the school (referred to as Site 1 and Site 2). The main focuses of this observation were: to examine day to day activities of the children, especially looking out for periods of unconstrained play; to consider how the children and staff interact with classroom artefacts, and consider if this interaction has any bearing on software interaction; and to come to an understanding of how much intervention is required from staff with respect the children and their activities (again paying special attention to periods of unconstrained play). The observation was performed over 3 weeks.

During a given session the children and staff present at a site were observed while they went about the normal activities of the day, with emphasis given to those children diagnosed with autistic spectrum disorders (two at Site 1 and four at Site 2). These children ranged in age from five to eight, with five males and one female. Their positions on the autistic spectrum ranged from mid to high functioning, with four of the six functionally non-verbal. Special attention was paid to activities during 'choosing time'10 minute free play sessions occurring four to six times per day, during which students were encouraged to select an activity to engage in.

Manual notes were taken by the first researcher for later analysis. Behaviour was observed and inferences regarding intent and motivation were noted when those behaviours were recorded. This was an exploratory investigation designed to discover and/or help model how the children went about their daily activities.

The IWB in use in the classrooms is a Smartboard front projection device that allows users to interact directly with software by contact with its surface, typically with their outstretched finger. The following observation is a sample of the interactions seen with the children and the Smartboard interactive whiteboard:

Participant A has been asked to 'write' his name on the Smartboard. He is encouraged by the staff to get up from his chair and move around the tables to stand in front of the Smartboard. Upon the Smartboard his name is positioned off to the lower right upon its surface. This is Participant A's first day using the Smartboard and he seems very tentative and anxious.
The teacher within the classroom appears to have expected this and stands close to Participant A, ready to help if required. Participant A continues to be unsure and has yet to touch the Smartboard. Very slowly, the teacher encompasses Participant A's hand with hers and guides his hand onto the Smartboard's surface. This done, the teacher pushes down with Participant A's hand on the area where the Participant A's name is 'resting' and, still pushing down, drags the name into a rectangular box positioned on the upper left hand side of the Smartboard in one long continuous motion. This operation complete, Participant $A$ is congratulated by all the staff in the classroom, with the other children being encouraged to join in. The sound this display generates seems to make Participant A uncomfortable and with a sudden discordant shriek, he rushes back to his chair and sits down. He has his hands over his ears and is rocking back and forth slowly. This reaction to the applause of the staff and other children seems to have been expected by the teacher and staff, and while in no way is Participant A being ignored, none of the staff show undue concern at this reaction. Another child is selected by the teacher to write his name upon the Smartboard...

The layouts of the teaching rooms at Sites 1 \& 2 are depicted in Figure 1. The IWBs at both sites are both positioned at the front of each classroom, and dominate a person's view upon entering. This means that any activity that uses the Smartboard, at either site, also dominates the available space of the classroom. Naturally, given this positioning, the IWB is the main medium used by the teachers to present information to the children (replacing the traditional blackboard or whiteboard within the classroom). The IWB is clearly within the teacher's 'territory', and its associated PC is not available for use by students. The childrens' seating-facing the IWB, with the teacher standing in front or beside the IWB-emphasizes that the teacher controls access to it. In effect, the IWB has replaced the whiteboard/chalkboard, and inherits the conventions of use for these traditional teaching tools.

Although the IWB sees frequent use at both sites, the activities are entirely teacher-directed and tied to group engagement. There appears to be an unspoken rule that the IWBs are used exclusively for curriculum based activities that involve the whole class - they are not available to the children during the free play 'choosing times'.
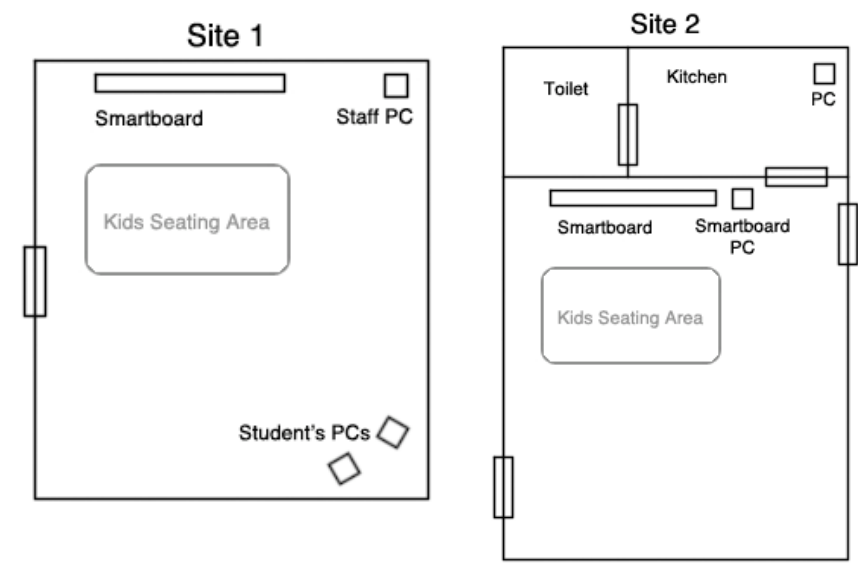

Figure 1a. Classroom layout at Figure 1b. Classroom layout at Site 2 . 
Site 1.

In both sites, the IWB was positioned at a height on the wall that seemed more appropriate for use by the teachers than the children. This positioning further reinforces the impression that the IWB is primarily for use by the teacher. Most children weren't tall enough to reach the upper area of the IWB surface. Both sites have a wooden step that the children use to offset the effect this wall position has on their use of the IWB-but balancing on a step can feel precarious, and limits the childrens' side-to-side movements.

Controls displayed by the software designed specifically for the Smartboard (e.g., buttons) were very large, even given the size of the IWB surface. These disproportionally large controls appear to serve two purposes: they counteract the problem of the upper surfaces being harder to reach by shorter users, and they accommodate the reduced levels of fine motor control within the younger user group.

Because the Smartboard is a front projection system, the silhouette cast by the user blocks a portion of the viewing surface and thus hides a proportion of the information displayed. Practice seemed to result in accommodation to this fact, as the more experienced children stood in profile (at least partially), extending the body part they were using as an interface point away from their body as a way of distancing the 'area of focus' from the 'area of shadow'.

The projection technology also impacts visibility of images on the board. To create a reasonably sharp image, the lights in the classroom must be dimmed or (preferably) turned off. But altering the lighting for the entire room affects what others in the class can do when the Smartboard is in use-further placing the IWB under the control of the teacher, to ensure that its use does not interfere with other learners.

\section{DEPLOYMENT OF FREE PLAY SOFTWARE PROTOTYPE}

A drawing package, 'Neon Chalk', was developed to support 'untethered' free play on the IWB. This software was installed at both Site 1 and Site 2, and the original intention was to test the usability and appeal of Neon Chalk with the six focus ASD children in the original observation study (Section 3), during 'choosing time'. However, the function of the IWB as a primary teaching tool rendered that strategy inappropriate. Further, only including those six children from the first study would cause undue distress to the other children within the classroom, who might feel bad at being 'left out'. This requirement, that all of the children at both sites 'have a turn' during a single school period, meant that the amount of time each child could interact with the Neon Chalk prototype was limited to 5 minutes. Those six children who were participating in this project had their user trials, or 'turns', videotaped, while the other children did not have their 'turns' videotaped or otherwise recorded, and their actions were not analyzed in the assessment of Neon Chalk.

The screen layout of Neon Chalk acknowledges that the IWB is positioned too high on the wall for children to access the entire screen (Figure 2). The drawing surface is maximized, so that the child is constrained only by his or her reach. As the child draws, a silhouette of a piece of chalk in the lower right hand corner grows shorter and shorter, representing the amount of the chalk used. Once the chalk is 'used up', pressing this control will renew the chalk supply (a full-sized chalk silhouette re-appears). This control is deliberately placed where the child can see it easily, and its large size is intended to attract attention to it and so prompt its use.

The small icons placed in the difficult-to-reach upper right corner are intended for use by the teacher, rather than the child. These buttons pause the game, toggle the sound off /on, and create screen shots of the child's drawing. These functions allow the teacher to quickly intervene if child is becoming agitated by the display or sound in the game, or to capture work to share with the child's parents/caregivers. Here, the child-unfriendly placement of the IWB on the wall is turned to an advantage by allowing 'teacher only' controls to be permanently placed on the interface without interfering with usability from the child's point of view.

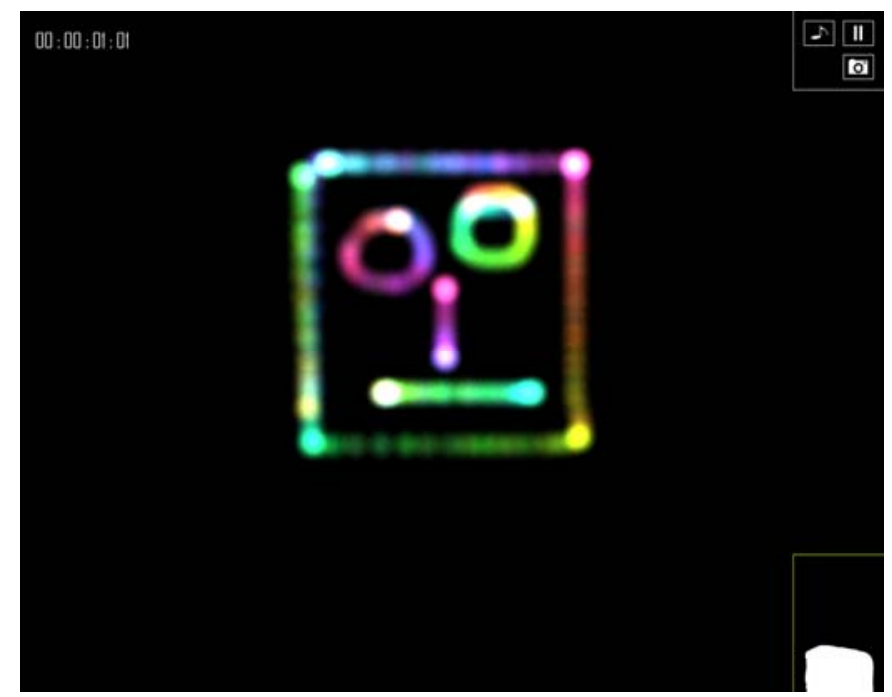

Figure 2. The Neon Chalk prototype with example image drawn using large multicoloured rainbow chalk setting.

The identification of the IWB as being under control of the teacher and its association with the formal curriculum will be much more difficult to overcome-despite the young age of the participants, these associations are already ingrained in the participants. For example, despite encouragement by the teacher to draw with Neon Chalk, Participant E displayed behaviours at the beginning of his user trial that was consistent with the way that the children use the IWB during formal lessons: at the beginning of his user trial Participant E ran up to the Smartboard, tapped its surface and then moved to sit down again. This is very similar to the behaviour observed in the initial observational study (Section 3), where during a lesson involving the IWB the children were asked to approach the Smartboard, push the correct button on screen and then go and sit down again.

This association with formal instruction appears to discourage unstructured play, at least initially in the use of Neon Chalk. During his user trial, Participant $\mathrm{C}$ seemed initially unsure of himself, and before touching the Smart Board asked, "What am allowed to draw?" The implication here seemed to be that the IWB was for work, and thus that what was accomplished upon it 
was likely to be judged right or wrong. There is a need to be cautious with this sort of attribution of thought, but given the IWBs at both Site 1 and Site 2 are used almost exclusively for curriculum based activities, this interpretation seems likely.

\section{CONCLUSIONS}

The physical environment of the classroom is not neutral; the arrangement of artefacts within the classroom setting supports certain behaviours by teacher and student, and impedes others [12]. Proshansky and Wolfe [10] make the distinction between direct and symbolic influences of the physical environment on behaviours within the classroom.

As an example of a direct influence, the placement of the IWB at a height most suitable for teachers impacts the children as users directly---they cannot reach parts of the IWB surface and so cannot interact with software controls placed on inaccessible portions of the IWB. This has obvious disadvantages - the usable space for software applications has been restricted-but in this case the shortcoming can be mitigated by careful interface design (the teacher-specific controls are placed in the upper right hand corner, inaccessible to the students).

This type of (negative) direct influence appears to be common with IWBs. Earlier studies of IWB use in middle schools identified many of the same technical problems as were apparent at the special needs school that participated in this study: the effect of sunlight in creating a glare or washing out the IWB display, difficulties associated with placement on the wall, and the shadow effect when the hand or body of the user blocks the light from the projector ([1], [5]).

As an example of symbolic influence, the seating of children facing the IWB and the clear inclusion of the IWB within the teacher's 'territory' implies that the IWB is under the control of the teacher. Within the classroom environment the Smartboard has replaced the whiteboard, which in the past replaced the blackboard, and as such it has inherited that artifact's legacy of belonging to the teacher. Because the IWBs are placed so as to be a focus for activity, when the Smartboard is used, the entire class needs to be involved. This means that the children will most likely have to take turns and that the activity the class will be engaged in will be an activity that focuses on curriculum content and not play. This symbolic ownership of the IWB by teachers restricts its use by the children within the classroom, despite the fact that its installation was motivated by a desire to empower the children and offer new aspects to their learning. These environmental factors have significant, and unexpected, ramifications for any software deployed to the Smartboard within the classroom, rendering it unlikely to be usable in practice for free play.

\section{ACKNOWLEDGMENTS}

We thank the students and staff at the special needs school for allowing us to participate in their work, and in turn for their participation in our study.

\section{REFERENCES}

[1] Beeland, W.D. 2002. Student engagement, visual learning and technology: can interactive whiteboards help? Action Research Exchange, 1,1 (Summer 2002). DOI=http://chiron.valdosta.edu/are/Artmanscrpt/volno1/bella nd_am.pdf

[2] Billingsley, J., Browning, B., and Wilting, K. 2006. Exploratory Play/Time: An investigation within three elementary classrooms Educational Insights, 10,1, (2006). DOI=http://www.ccfi.educ.ubc.ca/publication/insights/v10n0 1/articles/browningetal.html

[3] Dautenhahn, K. 2000. Design issues on interactive environments for children with autism. Proceedings International Conference on Disability, Virtual Reality and Associated Technologies (ICDVRAT), 153-161.

[4] Furneaux, B. 1984. Keeping the balance right. Special Education: Forward Trends, 11(2) (June 1984), 15-16.

[5] Hall, I., and S. Higgins. 2005. Primary school students' perceptions of interactive whiteboards. Journal of Computer Assisted Learning, 21, 102-117.

[6] Keay-Bright, W. 2007. The Reactive Colours Project: Demonstrating Participatory and Collaborative Design Methods for the Creation of Software for Autistic Children, Design Principles \& Practices: An International Journal, 1(2), 133-151.

[7] Keay-Bright, W. 2007. Can computers create relaxation? Designing ReacTickles $($ software with children on the autistic spectrum. NCDN, 3(2), 97-110.

[8] Piaget, J. 1962. Play, dreams and imitation. W.W. Norton and Company, Ltd.

[9] Preissler, M. A. (2006). Play and Autism: Facilitating Symbolic Understanding, 231-250. In Play = Learning . Oxford University Press.

[10] Proshansky, E., and Wolfe, M. 1974. The physical setting and open education. School Review, 82, 557-574.

[11] Vygotsky, L. S. (1978). Mind in society: The development of higher psychological processes. Cambridge, MA: Harvard University Press.

[12] Weinstein, C.S. 1981. Classroom design as an external condition for learning. Educational Technology (Aug 1981), $12-19$. 